\title{
Intelligent Negotiation Mechanism for Supporting the Interoperability within the Sensing Enterprise
}

\author{
Aurelian Mihai Stanescu *, Adina Cretan **, Carlos Coutinho***, Ricardo Jardim-Goncalves*** \\ * Faculty of Automatic Control and Computer Science, University Politehnica of Bucharest, \\ Romania (e-mail:ams@cpru.pub.ro) \\ * * Computer Science Department, "Nicolae Titulescu" University of Bucharest, \\ Romania (e-mail: badina20@yahoo.com) \\ ***CTS, Departamento de Engenharia Electrotecnica, Faculdade de Ciencias e Tecnologia, Universidade \\ Nova de Lisboa,UNINOVA, Portugal (e-mail: c.coutinho@fct.unl.pt,rg@uninova.pt)
}

\begin{abstract}
The Sensing Enterprise is a novel concept that refers to an enterprise anticipating future decisions by using multi-dimensional information captured through physical and virtual objects. The Sensing Enterprise concept is shifting focus towards a borderless enterprise, having at its core the collaboration and continuous interactions among smart objects and systems. But in the actual competitive and global business context, the maintenance of the collaboration environment through the interoperation among heterogeneous smart virtual and physical objects in a collaborative organizational environment becomes difficult to achieve. Therefore, in a dynamic context a change in any component of the networked partners affects the others, creating difficulties to sustain operating networked environment. In this respect, this paper proposes an intelligent negotiation framework as a key mechanism to achieve and maintain the interoperability between the organisations' smart objects and applications, and its validation in an industrial scenario. To allow a sustainable, flexible and generic approach towards the infrastructure implementation in global scale, a cloud-based platform is proposed for setting of the Sensing Enterprise framework.
\end{abstract}

Keywords: Negotiation; Sensing Enterprise; Service-orientation; Enterprise Interoperability; Cloud-based environment.

\section{INTRODUCTION}

The advent of the Internet and more recently the cloudcomputing trend have led to the development of various forms of virtual collaboration in which the organizations are trying to exploit the facilities of the network to achieve higher utilization of their resources. Therefore, they tend to work in networks of specialised and dedicated partners which by leading their focus to their specific business are able to provide added value to the continuously increasing competitive market.

This value started as simple data exchanges and is growing towards leasing of services to entire business functionalities to the creation of Virtual Organisations able to provide customers with more complete and fully featured solutions (Sacala et al, 2012).

Moreover, the Sensing Enterprise concept aims to support new models of business that enhance cooperative networking among the wide range of enterprise assets through their entire lifecycle and enabled by sensing capabilities of smart components (Hauswirth and Soldatos, 2012). Thus, these enterprises need to develop dedicated business areas to handle the seeking for new partnerships, with its inherent need for interoperation, while maintaining the interoperability regarding the current ones. With a growing number of players and changes, this will rapidly lead to a non-interoperability scenario within the business network. To reach sustainable operation, companies need to continuously negotiate, create and maintain the interoperability among them.

This paper proposes an intelligent negotiation framework in order to support interoperability in systems and applications by negotiating the changes for enterprise interoperability with the players of business-to-business interactions, to support the development and implementation of the Sensing Enterprise concept in industrial setup. Section 2 presents the relation of this subject with other existing research. Section 3 describes the architecture of the proposed negotiation framework in which the interactions take place. Section 4 presents the industrial validation case and, finally, section 5 provides the conclusions and final considerations.

\section{RELATION TO EXISTING THEORIES AND WORK}

The Sensing Enterprise concept refers to an enterprise anticipating future decisions by using multi-dimensional information captured through physical and virtual objects and providing added value information to enhance its global context awareness (Lazaro et al., 2012). It aims to enhance the global knowledge of business systems through the development of applications services and solutions by smart components. These components may be physical or virtual, like smart sensors, enhanced tags, intelligent agents, or smart objects, enabling a continuous awareness and improvement of business operations in a digital environment that will bring 
new business trends and models not possible otherwise. Through it, new business models can be developed enabled to support cooperative networking among the enterprise assets and artefacts through integration of sensing capabilities. Thus, the Sensing Enterprise concept aims to create new forms of enterprises, where collaboration and continuous interactions among smart objects are central to the new scenario, shifting the focus on the interaction among systems, and supporting the notion of smart dust in the clouds as a new form and evolution of the state of the art computing systems.

Sensor network applications can be composed by many sensors with different types, models and manufacturers. As the amount of data sources and heterogeneity increases, the difficulty to manage environmental data also increases. Koga and Medeiros (Koga and Medeiros, 2011) try to solve the heterogeneity problem using Enterprise Service Bus (ESB) architectures and Complex Event Processing (CEP) theory to deal with sensor data. In CEP, an event is an object signifying an activity with three aspects (Form, Significance and Relativity) that a computer can process (Luckham, 2007).

Other research papers (Barthe-Delanoë et al., 2012; Marterer et al., 2012) combine the Event-Driven Service-Oriented Architectures (ED-SOA) principles (Taylor et al., 2009) with CEP principles (Luckham and Schulte, 2011; Etzion and Niblett, 2010) in order to tackle organizations' collaboration issue through a model-driven Mediation Information System (MIS) to support the interoperability among the partners.

Outlining the key position of information systems (IS) inside an organisation, Benaben et al. (Benaben et al.,2012) state that the main issue is to ensure that IS of the partners involved in the collaboration are able to work together to constitute a coherent and homogeneous set of IS - the IS of the collaborative situation. Also, the need of agility is crucial for interoperable IS in order to manage any changes, any evolution, and any information that could challenged collaborative processes' accuracy and relevancy (BartheDelanoë et al., 2012). To address this issue, Benaben and Pingaud (Benaben and Pingaud, 2008) propose the Mediation Information System Engineering Project (MISE Project) which aims at providing collaborating organizations with a Mediation Information System (MIS) able to support the interoperability of a collaborative network. Also, the architecture of the MIS meets the need of agility by detecting the events which could have an impact on the crisis response and defining an adaptation regarding these events. Furthermore, the MISE project takes a model-driven approach to develop a complete MIS design method, taking into account the semantic reconciliation between business and technical levels.

Nevertheless, the need for negotiations in a scenario of increasingly complex networking environments is urged by scenarios where enterprises, by changing their model, trigger a chain event of model changes on all its network partners/dependents. For instance, enterprise A wanting to be interoperable with a new enterprise B changes its model, which leads all it dependents (suppliers, partners, customers) to also change. Recursively, all their dependencies are then also impacted, in a pyramid scheme. If used, negotiations could instead determine that it would be simpler to make the change on enterprise $\mathrm{B}$ or to reach a cooperating/consensus solution, or even taking an extreme decision that interoperability between A and B is not worthwhile or advisable.

The proposed framework is based on a negotiation mechanism and a decision-support system for the negotiation of interoperability changes, which allows enterprises to take decisions over the option that will best suit their needs, resulting from the analysis of the required changes and motivations, benefits, opportunities and threats, and the resulting impact of proposed changes in terms of resources, effort, cost and time, with the purpose of reducing downtime and effort towards (re-)achieving interoperability.

To support the modelling of the enterprise business, ModelDriven Architectures (MDA) is used to define the vertical business models from concepts to implementation (Coutinho et al., 2011). Interoperability among enterprises shall be Model-Driven (MDI) as well to support the horizontal transformations for interoperability among the parties throughout the MDA levels (Jardim-Goncalves et al., 2010). MDA defines three main levels for application definition: a Computation-Independent Model (CIM), where business concepts are modelled and rules are defined; its transformation into a Platform-Independent Model (PIM) where the concepts and rules are converted into activities, structures, tasks and algorithms, while still maintaining independence from the implementation platform; finally, the transformation into a Platform-Specific Model (PSM) where the implementation towards code and applications targeted to a platform is performed (Grilo et al., 2006), (Nie et al., 2010).

\section{NEGOTIATION FRAMEWORK TO SUPPORT ENTERPRISE INTEROPERABILITY}

The proposed framework captures the relevant information from enterprises regarding interoperability both in the Technology view and in the Business view, modelling this information in multiple abstraction levels, and using negotiation to determine the most appropriate interoperability solutions, which are then built-up in the shape of services in a SOA, deployed in a scalable cloud-based environment.

The requirements analysis for achieving sustainable interoperability is supported by a set of questionnaires and surveys to properly describe the business and identify its interoperability needs. The proposed methodology starts by modelling enterprises into MDA (Jardim-Goncalves et al., 2011). Thus, the basic foundations (services and infrastructure) of each business operation, gathered from the questionnaires, are modeled into a MDA CIM. The business models are progressively transformed from concepts (at CIM level) to rules, algorithms, ontologies and structures (at PIM level) (Jardim-Goncalves et al., 2006), and, finally, to specific implementation (at PSM level) services. These PSM models are implemented as cloud-based services in ServiceOriented Architectures (SOA, SaaS) (Jardim-Goncalves and Grilo, 2010). It also included the definition and maintenance of a reference ontology which supports the semantic interoperability of the framework, needed for the seamless understanding of the underlying business. Hence, CIM 
defines at the most abstract level the mechanisms that will support the interoperability negotiation, split in two layers (Figure 1).

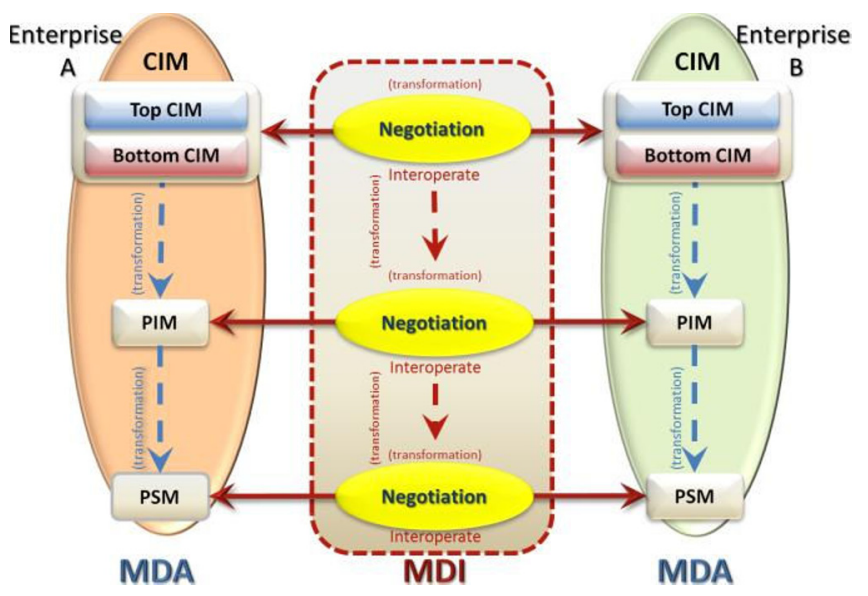

Fig. 1. Enterprise modelling using MDA, MDI and negotiations

The Top CIM handles the business strategic functionalities according to the requirements and needs, which include the interoperability needs with the existing partners and the additional self-improvements due to e.g. adoption of new technologies, supported platforms, lessons learned and best practices. The Bottom CIM handles the operational functionalities that are relevant to the updates and adaptations towards new partners, and new interoperability challenges. Negotiations are conducted in all MDA layers as means for deciding the MDI horizontal transformations that are required for achieving interoperability, i.e. interoperability in concepts and definitions, in structures, ontology and business flows, and in middleware, data, interfaces and formats. The framework's negotiation mechanism has the purpose to model, conduct and moderate properly the negotiations for interoperability changes when they are detected and needed, implementing the negotiation rules for achieving interoperability in all MDA layers.

Each negotiation is organised in three main steps: initialisation; refinement of the job under negotiation; and closure (Sycara and Dai, 2010). The initialisation step allows to define what has to be negotiated (Negotiation Object) and how (Negotiation Framework) (Duan et al, 2012). In the refinement step, participants exchange proposals on the negotiation object trying to satisfy their constraints $(\mathrm{Hu}$ and Deng, 2011). Closure concludes the negotiation.

The architecture of the proposed framework, based on a Multi-Agent Systems (MAS) environment, is structured in three main layers, as seen on Figure 2 (Cretan et al., 2012a).

The top negotiation layer performs the task of Negotiation Manager, which implements the high-level business decisions that need to be taken for the negotiation, (e.g., starting a new negotiation; making negotiation proposals; accepting/rejecting proposals) (Cretan et al., 2012b). Its rules are defined on the Bottom CIM, managing the negotiation parameters and communicating with the lower layers using web-services (Coutinho et al., 2012).

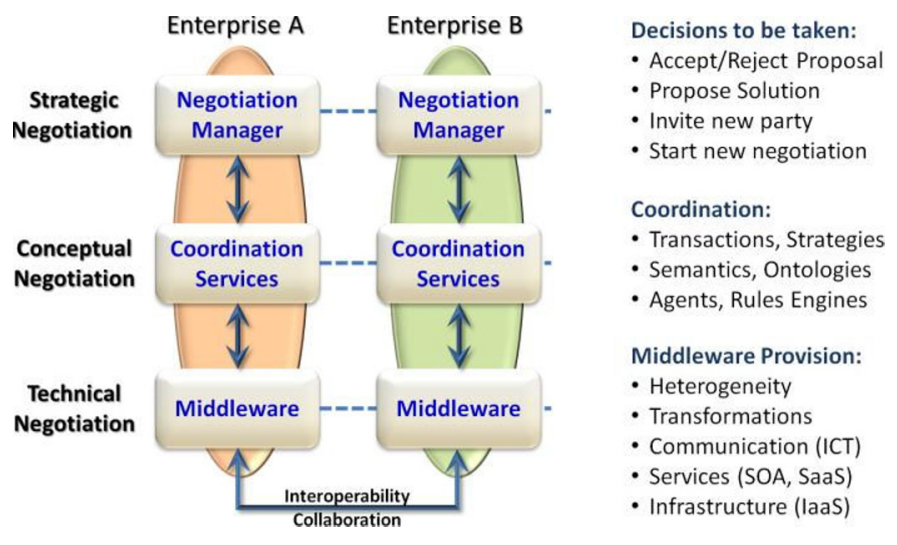

Fig. 2. The architecture of the Negotiation Framework

A second negotiation layer handles the Coordination Services (CS), a module which has the purpose to coordinate and assist the negotiations at a global level (i.e., negotiations with different participants on different jobs) and at a specific level (i.e., negotiation on the same job with different participants). It handles all issues regarding communication at this layer level (synchronisation among the CSs of the several parties that are taking place in the negotiation). It also manages the on-going transactions, the negotiation data persistence, and the semantic discrepancies among the negotiating parties.

Finally, a lower negotiation layer, Middleware implements communication services and provides support for the aspects related with the basic infrastructures, handling the heterogeneity related with multiple negotiation players, which shall interact using an Enterprise Service Bus (ESB) for dealing with interoperability issues (Cretan et al., 2012b). The overall functional structure of the framework is described in Figure 3.

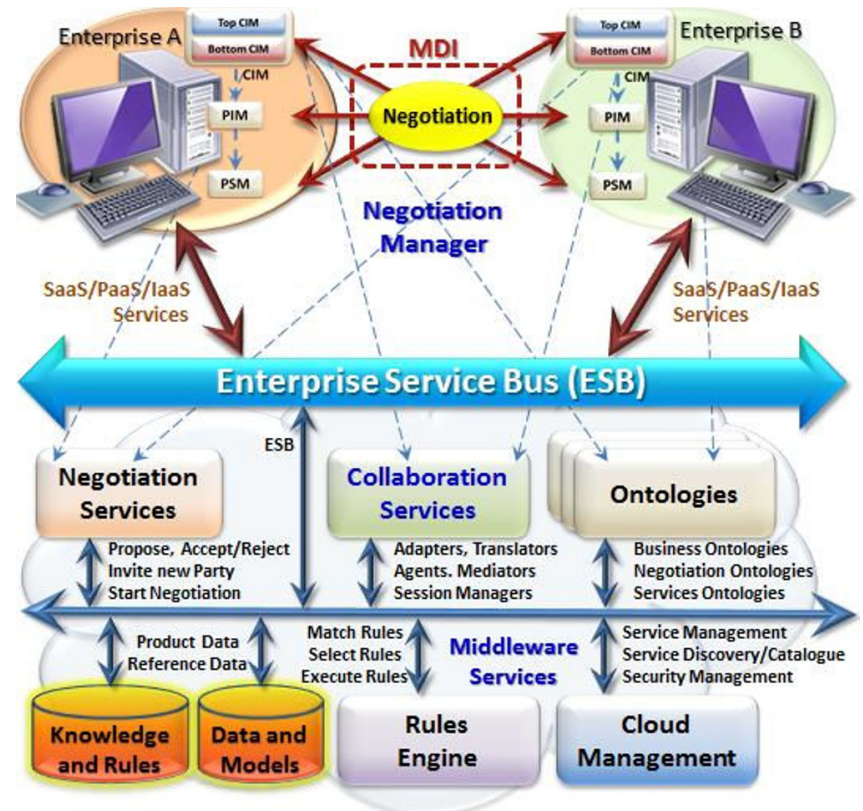

Fig. 3. Negotiation framework to support Enterprise Interoperability

The resulting multi-levelled models from MDA and MDI are implemented in a set of dedicated services for performing the 
interoperability among the parties. The definition of a set of negotiation services includes MAS for detecting changes in the interoperability environment and trigger negotiations, and the services which perform the negotiation themselves, according to a dedicated negotiation mechanism. The negotiation process is defined and coordinated by a set of negotiation rules implemented in a Rule Engine for the Java Platform (JESS) and using agents with the Java Agent Development Framework (JADE) (Kadar et al., 2013).

To develop and manage the reference ontology, the framework uses the MENTOR (Sarraipa et al., 2010) methodology, to allow heterogeneous business concepts to be harmonised into a common understanding in the business network, thus enhancing interoperability.

The negotiation process is supported by an interoperability ESB on top of which a set of dedicated services (Papazoglou et al., 2008) implement the business requirements and operations, and also the negotiation mechanism in a SOA. To manage the issues regarding size and scalability, the SOA infrastructure is implemented on top of a Cloud-based Infrastructure as a Service (IaaS) system (Sharma and Sood, 2011), hosted by a Software as a Service (SaaS) business paradigm (Buyya et al., 2009). Also, the communication between the enterprises and the cloud-based environment is performed through the use of ESB.

The data models and structures are also stored in a cloudbased infrastructure (IaaS), and its access, its models and data exchange for supporting the negotiation parameters, ontologies and other entities are defined and modelled using standard reference models (Jardim-Goncalves et al., 2007).

\section{INDUSTRIAL SCENARIO FOR FRAMEWORK VALIDATION}

This Framework is being validated using a case study from European Space Agency - Concurrent Design Facility (ESACDF) (Kolfschoten et al., 2010). This department performs feasibility studies over the design of space missions, and does so by using the concept of Concurrent Engineering, splitting the mission into a set of design disciplines (e.g., Mission Analysis, Power, Structures) each of which is handled by a specific team (Ton et al., 2008).

The negotiations among design domains are performed in a set of closed "war-room" sessions where all involved domains and stakeholders are present or represented and where each domain presents its design solutions and the corresponding impact on the mission design. Interoperability in this explosive and highly competitive scenario is assured by the study Team Leader which moderates the discussions and a Systems engineer and related assistants which provide local support to the domain engineers. The seniority of the domain experts which are selected to participate in the study is also a crucial factor to improve interoperability.

The infrastructure includes the definition of a space ontology and the data storage is performed using a database modelled using ISO10303 STEP and Express. In the ESA-CDF environment the design of each future space mission is split into a set of engineering domains, where each domain engineering team performs its design using different tools (e.g., CATIA, STK, Matlab) and is provided and supported by a network of partners and suppliers (Coutinho et al., 2008). Therefore interoperability in this case is defined in two levels, the interoperability between each domain and its tools/partners/suppliers towards the target of defining the domain design or vision of the mission, and interoperability among the various domains of a mission-related study, where all the domains negotiate and compete for their interests into setting the values for mission-related parameters (e.g., Spacecraft dry mass, Electrical power, Solar panel dimensions, Launch mass).

Despite these factors, it is quite difficult to maintain clear interoperation, and as studies tend to be more complex, with new concepts, methodologies, formats and terminologies, and data has more dependencies, interoperability will easily break apart, leading to problems in the design integration and to a lot of rework.

Furthermore, the fact that each domain has its own set of dependencies to tools, suppliers and partners makes the coherence of the knowledge among the whole study lifecycle tremendously difficult, as the number of communicating and interoperating channels tends to increase exponentially with the growth of the supply chain.

According to the defined approach, each ESA domain is modelled under the Sensing Enterprise concept into MDA and MDI, where the top CIM level defines the view of each domain on the space mission, the concepts and functionalities, and also the negotiation and interoperability needs. These models are progressively transformed into a PIM, and finally into a PSM which defines a specific set of services dedicated to interoperability, (e.g., adapters, translators, proxies and converters). These specific services are then combined with other framework services which concern Negotiation Services, Coordination Services, Ontology Services, and other generic Collaboration Services.

These services and their associated structures are assigned to interoperability nodes among sets of entities using multidimensional information captured through physical and virtual objects which share interoperability needs and requirements. This leads to a progressive but rapid consumption of the system resources, and as the interoperability links are no longer needed, these resources are released, thus the system requirements are very demanding while they need to be flexible. Hence, the natural selection of a cloud distributed IaaS to store the framework infrastructure, and of a SaaS platform to host the service sets.

The proposed proof-of-concept scenario connected a set of design domains in a stable interoperable environment, exchanging mission design data. The conflicting situation occurred when the Structures domain (responsible for the definition of the structural architecture of the designed spacecraft) wanted to start working with a new provider tool for CAD drawings, which have a different format than the previously used drawings. So, this is not a problem regarding the business itself (the design results) but instead it is a problem concerning the interoperability among the different domains involved. 
Firstly, the tools for ontology harmonisation provided necessary means to define clearly the new concepts, terms and formats (e.g., planes, connectors, vectors, surfaces), their hierarchy and relationship; so that there was no conflict or misunderstanding with regards to the terms that already existed. This harmonisation led to the update of the reference ontology used to integrate all domains.

The next step was to propose the new tool/format using the negotiation mechanism. The Negotiation Manager of the Structures domain made the proposal, defining the pros and cons of using the new tool instead of the previous one. Here, several heterogeneous arguments may be used, (e.g., economic factors, accuracy, integration, performance, new opportunities, trends and fashions). Therefore, the initiating Negotiation Manager has defined the Negotiation Object described by attributes (e.g., cost; quality; type) and the Negotiation Framework.

Through the agent-based negotiation architecture the proposal was then sent to the Negotiation Managers of the other interoperating parties. Some of the other domains considered that the new format is better for their work and accepted the proposal, others didn't think the same way and rejected the proposal, and others have submitted a counterproposal to the requester and thus, the negotiation process began. During this process, a Negotiation Object is manipulated. This data structure represents the different information related to the negotiation under consideration. The communication process among the agents that conduct the negotiation proposals is made by the common middleware bottom-layer of the negotiation architecture.

The negotiation process was conducted until all proposal/counter-proposal cycles were properly finalised. A cycle is finalised when the parties arrive at a common understanding (i.e., in this case a new common format) or when one of the parties ends the negotiation with a clear reject (i.e., in this case a decision to keep using the old format).

The results of the submission of these proposals through the decision-support system were that the new format provided good opportunities for new markets, better performance and accuracy; hence it was worth to advance to the new format. On the other hand, maintaining the interoperability with the refusing parties was important, so it was decided that an adaptor would be built so that the old format would still be available. Considering the number of domains that had refused the new solution, it was found more efficient for the Structures domain to ensure that the information presented in the new format would be available also on the old, and clearly determined separate interoperating environments, with the new and the old formats.

The outcome of the negotiation process allowed the new tool and formats to be used on the current and the next studies, enhancing the quality, performance and accuracy of the design while permitting new opportunities and markets, improving the trust and relationship among the interoperating domains and developing negotiation skills knowledge which allowed future negotiations to spend less time.

\section{CONCLUSIONS AND FUTURE WORK}

This paper proposes an intelligent negotiation framework to manage parallel and concurrent negotiations in order to achieve and maintain the interoperability between the organisations' systems and applications, and its validation in an industrial scenario developed under the novel Sensing Enterprise concept. The adoption of cloud-computing allows this procedure to be based on seamless services, accessible by everyone in any part of the network.

Currently, interoperability among the involved parties in a negotiation is often not reached or maintained due to failure in adapting to new requirements, parties or conditions. Using the proposed adaptive platform leads to a seamless, sustainable interoperability, favoring its maintenance across time. The ability to reach and interoperate with more parties leads to new business opportunities and stronger and healthier interactions. The sequence of this research shall comprise the completion of this framework with a contract management process and a renegotiation mechanism.

With respect to the framework middleware, future research shall include handling issues regarding the security and resilience of the stored negotiation data in the cloud, and managing privacy aspects as the negotiating parties should be able to seamlessly interoperate but still to maintain their data free from prying eyes; also several issues need to be solved from non-disclosure of participating parties to secure access to the negotiation process.

\section{ACKNOWLEDGEMENT}

The authors wish to acknowledge the support of the European Commission through the funding of the UNITE, MSEE and IMAGINE FP7 projects, and the European Space Agency Concurrent Design Facility (ESA-CDF) for their support in the development of the business case presented in this paper.

\section{REFERENCES}

Barthe-Delanoë, A.M., Bénaben, F., Carbonnel, S., Pingaud, H. (2012). Event-Driven Agility of Crisis Management Collaborative Processes. Proceedings of the 9th International ISCRAM Conference, Vancouver, Canada, April 2012

Benaben, F., Pingaud, H. (2008). The MISE project: a first experience in Mediation Information System Engineering. In: 5th Italian Chapter of AIS, Paris

Benaben, F., Boissel-Dalliera, N., Pingaud, H. and Lorre, J.P. (2012). Semantic issues in model-driven management of information system interoperability. International Journal of Computer Integrated Manufacturing, Vol. 0, Issue 0 , pages $1-12$

Buyya, R., Yeo, C.S., et.al (2009). Cloud Computing and Emerging IT Platforms. Future Generation Computer Systems, Vol. 25(6): 599-616, Elsevier Science.

Coutinho, C., Relvas, A., Richardson, R., Ribeiro, A., Dunne, C. (2008), Domain Design Application (DDA) and enhancements of communication layer for CDF, in $3^{\text {rd }}$ International Workshop on System \& Concurrent Engineering for Space Applications, (SECESA'08).

Coutinho, C., Cretan, A., and Jardim-Goncalves, R. (2011). Sustainable Interoperability Framework for supporting 
Negotiation Processes. The 6th International Conference on Interoperability for Enterprise Systems and Applications, Valencia, Spain, 20-23 March 2012 (IESA'12).

Coutinho, C., Cretan, A., and Jardim-Goncalves, R. (2012). Cloud-based negotiation for sustainable Enterprise Interoperability. The 18th International ICE Conference on Engineering, Technology and Innovation, Munich, Germany, 18-20 June, 2012 (ICE'12).

Cretan, A., Coutinho, C., Bratu, B., and Jardim-Goncalves, R. (2012). A Framework for Sustainable Interoperability of Negotiation Processes. The 14th IFAC Symposium on Information Control Problems in Manufacturing (INCOM'12), 14(1): 1258-1263, Elsevier, DOI: 10.3182/20120523-3-RO-2023.00240

Cretan, A., Coutinho, C., Bratu, B., and Jardim-Goncalves, R. (2012). NEGOSEIO: A Framework for Negotiations toward Sustainable Enterprise Interoperability. IFAC Journal Annual Reviews in Control, Vol. 36, Issues 2, pp. 291-299.

Duan L., Dogru M., Ozen U., Beck J. (2012). A negotiation framework for linked combinatorial optimization problems. Autonomous Agents and Multi-Agent Systems, Volume 25 (1), pp. 158-182, Springer Netherlands

Etzion, O. and Niblett, P. (2010). Event Processing in Action. Manning, Stamford.

Grilo, A., Jardim-Goncalves, R., Steiger-Garcao, A. (2006), Challenging the Interoperability in the Construction Industry with MDA and SOA. Computers in Industry, Vol. 57, Issues 8-9.

Hauswirth, M., Soldatos, J. (2012). Sensing an Enterprise Semantic Cloud Based IoT Middleware. EU OpenIoT Project, FinES Cluster Meeting, Aalborg, May, 9th, 2012

Hu, J., Deng, L. (2011). An Association Rule-Based Bilateral Multi-Issue Negotiation Model. In Computational Intelligence and Design (ISCID), Fourth International Symposium, Volume 2, pp. $234-237$

Jardim-Goncalves, R., Figay, N., Steiger-Garcao, A. (2006), Enabling interoperability of STEP Application Protocols at meta-data and knowledge level. International Journal of Technology Management (IJTM).

Jardim-Goncalves, R., Agostinho, C., Malo, P., SteigerGarcao, A. (2007), Harmonising Technologies in Conceptual Models Representation, in International Journal on Product Lifecycle Management (IJPLM).

Jardim-Goncalves, R., and Grilo, A. (2010). SOA4BIM: Putting the building and construction industry in the Single European Information Space. Automation in Construction, Vol. 19, pp. 388-397.

Jardim-Goncalves, R., Agostinho, C., and Steiger-Garcao, A. (2010). Sustainable Systems' Interoperability: A reference model for seamless networked business. The IEEE International Conference on Systems, Man, and Cybernetics (SMC 2010), pp. 1785-1792.

Jardim-Goncalves, R., Sarraipa, J., Agostinho, C., and Panetto, H. (2011). Knowledge Framework for Intelligent Manufacturing Systems. Journal of Intelligent Manufacturing, Vol. 22, Issue 5, pp. 725-735.
Kadar, M., Cretan, A., Muntean, M., and Jardim-Goncalves, R. (2013). A Multi-Agent Based Negotiation System for Re-establishing Enterprise Interoperability in Collaborative Networked Environments. The 15th International Conference on Computer Modelling and Simulation (UKSim 2013), Cambridge, United Kingdom, 10-12 April 2013, pp. 190-196.

Kolfschoten, G., Matthyssen, A. and Fijneman, M., (2010), Theoretical foundations for Concurrent Design. The 4th International Workshop on System \& Concurrent Engineering for Space Applications (SECESA 2010).

Lazaro, O., et al. (2012). Risk Management - Current Issues and Challenges, Chapter 13: Integrated and Personalised Risk Management in the Sensing Enterprise, ISBN 978953-51-0747-7, DOI: 10.5772/50275

Luckham, D. (2007). The power of events: An introduction to complex event processing in distributed enterprise systems. The 5th ed., Addison-Wesley, Boston.

Luckham, D. and Schulte, W. R. (2011). Event Processing Technical Society, Event Processing Glossary, Version 2.0

Marterer, R., Moi, M., Koch, R. (2012). Event-driven architecture for emergency operations and trainings. Proceedings of the 9th International ISCRAM Conference, Vancouver, Canada, April 2012

Nie, L., Xu, X., Chen, D., Zacharewicz, G., and Zhan, D. (2010). GRAI-ICE Model Driven Interoperability Architecture for Developing Interoperable ESA. In Enterprise Interoperability IV (Springer), pp. 111-121.

Papazoglou, M.P., Traverso, P., Dustdar S., Leymann, F. (2008). Service-Oriented Computing: A Research Roadmap. International Journal of Cooperative Information Systems, 17(2), 223-255.

Sacala, I.S., Moisescu, M.A., Sacala, M. (2012). Towards the Development of Future Internet Enterprise Systems. Romanian Statistical Review Supplement, Vol. 60, Issue 2, pp. 472-474.

Sarraipa, J., Jardim-Goncalves, R., and Steiger-Garcao, A. (2010). MENTOR: an enabler for interoperable intelligent systems. International Journal of General Systems, Vol. 39 (5), pp. 557-573.

Sharma, R., Sood, M. (2011). Cloud SaaS and Model Driven Architecture. Proc. of Intl. Conf. Advanced Computing and Communication Technologies (ACCT 2011).

Sycara, K., Dai, T. (2010). Agent Reasoning in Negotiation. Advances in Group Decision and Negotiation, Volume 4, Handbook of Group Decision and Negotiation, Part 4, pp. 437-451

Taylor, H., Yochem, A., Phillips, L. and Martinez, F. (2009). Event-Driven Architecture: How SOA enables the RealTime Enterprise. Addison-Wesley, Boston.

Ton, A., Coutinho, C., Richardson, R., Relvas, A., Haenisch, J., Christiansen, T. (2008). The ESA OCDS Project Enhancing the Concurrent Design Concept. 10th NASAESA Workshop on Product Data Exchange (PDE'10). 